\title{
Acelerador forte e concavidade da função consumo em modelos neokaleckianos: rediscutindo o crescimento liderado pelos salários
}

Strong accelerator and concavity of the consumption function in neokaleckian models: rediscussing the wage-led growth

Vivian Garrido Moreira (1)

(1) Universidade Federal de Santa Catarina

\begin{abstract}
This essay proposes an alternative for generalization, under certain conditions, of the concept of strong accelerator, in the sense given by Bhaduri and Marglin (1988 and 1990) model, using a concave consumption function. Based on this, it demonstrates that the possibility of a wage-led growth becomes very probable and no more an eventual case. Symmetrically, it makes improbable the possibility of occurrence of profit squeeze. The text also analyses critically the Bhaduri and Marglin canonical model, presenting questions about its clarity as a source of criticism of a range of neokaleckians growth models that have been published previously.
\end{abstract}

\section{Keywords}

robinsonian stability, strong accelerator, Bhaduri and Marglin, wage-led growth, profit-squeeze.

JEL Codes E210, E250, O400.

\section{Resumo}

Este ensaio propõe uma alternativa de generalização, sob certas condições, do conceito de acelerador forte, no sentido dado a ele dentro do modelo crítico de Bhaduri e Marglin (1988 e 1990), a partir de uma função consumo côncava. Com base nisso, demonstra que a possibilidade de um regime de crescimento liderado pelos salários deixa de ser um caso eventual, tonando-se consideravelmente provável. Simetricamente, torna improvável a possibilidade de ocorrência de compressão dos lucros (profit-squeeze). O texto também analisa criticamente o próprio modelo canônico de Bhaduri e Marglin, apresentando questionamentos sobre sua clareza enquanto fonte de crítica a uma série de modelos de crescimento neokaleckianos que o antecedem.

\section{Palavras-chave}

estabilidade robinsoniana, acelerador forte, Bhaduri e Marglin, crescimento liderado pelos salários, compressão de lucros.

Códigos JEL E210, E250, O400. 


\section{Introdução}

De acordo com Bhaduri e Marglin (1988), ${ }^{1}$ uma série de modelos tratando do problema da acumulação de uma perspectiva particular foi inaugurada com base em Joan Robinson (1956 e 1987 [1962]). Essa condição específica foi por eles denominada acelerador forte. $O$ presente artigo trata da problemática envolvida nessa condição e também demonstra que, a partir da introdução de uma função consumo bastante realista (particularmente para os capitalistas), a possibilidade de um regime de crescimento liderado pelos salários deixa de ser um caso eventual, tornando-se consideravelmente provável (logo, tornando improvável a possibilidade de ocorrência de compressão dos lucros ou profit-squeeze).

A argumentação prosseguirá através de mais quatro seções e uma conclusão. A próxima apresenta os conceitos-chave de estabilidade robinsoniana e de acelerador forte. A seção 3 apresenta o modelo de Bhaduri e Marglin que foi utilizado para construir a crítica aos dois conceitos anteriores. A seção 4 contribui para a discussão aberta pela crítica anterior, através da proposição do formato alternativo (côncavo) para a função consumo, procurando retomar o acelerador forte a partir dessa proposição. A seção 5 avalia a possibilidade de um regime de crescimento liderado pelos salários com base na função consumo apresentada. Ao final, as conclusões gerais do artigo são apresentadas na seção 6 .

\section{A estabilidade robinsoniana e o acelerador forte}

Os conceitos de estabilidade robinsoniana e acelerador forte aparecem em Bhaduri \& Marglin (1988), a partir do momento em que os autores se propõem a identificar algo que não havia sido bem esclarecido na equação de Cambridge e que deu lugar a interpretações antagônicas sobre regimes de crescimento. $O$ ponto de partida se resume em detalhar a composição da taxa de lucro com o objetivo de compreender as diferentes relações possíveis entre taxa de lucro e taxa de acumulação. A fim de explicitar seus componentes, a taxa de lucro pode ser decomposta da seguinte forma:

\footnotetext{
1 Doravante, B\&M.
} 


$$
r=\frac{R}{K}=(R \mid Y)\left(Y \mid Y^{*}\right)\left(Y^{*} \mid K\right)=\sigma u a
$$

onde $a=\left(Y^{*} \mid K\right)$ é o coeficiente técnico produto-capital máximo (ou potencial), constante no curto prazo, $u=\left(Y \mid Y^{*}\right)$ é o grau de utilização, e $\sigma$ é a parcela dos lucros na renda (dada a partir da margem de lucro). ${ }^{2}$ Por definição, um aumento da parcela de lucros na renda requer uma redução da parcela dos salários. O fato fundamental é que os salários representam um custo de produção de um lado e, como é suposto que os trabalhadores gastam toda a sua renda (e os capitalistas não), representam plena injeção de demanda por outro lado, o que contribui para a redução do grau de utilização e, portanto, redução da taxa de lucro. Então a redução da parcela dos salários (aumento da parcela/margem de lucros) exerce efeito ambíguo sobre a taxa de lucro: um efeito de aumento de $\sigma$ e um efeito de redução de $u$. Essa ambiguidade na composição da taxa de lucro nem sempre foi devidamente destacada. E é a partir dela que se pode definir os conceitos de estabilidade robinsoniana e de acelerador forte, conforme propostos por B\&M. Para os efeitos deste artigo, podemos resumir a estabilidade robinsoniana ocorrendo quando:

- um dado aumento na parcela de lucros exerce efeito líquido contracionista sobre a demanda, logo, sobre o grau de utilização e nível de produto; simetricamente, um dado aumento da parcela de salários exerce efeito líquido expansionista sobre demanda/grau de utilização/nível de produto.

Isso implica dizer que, independentemente do efeito líquido do aumento da parcela/margem de lucros sobre a taxa de lucros e desta sobre o investimento, seu efeito líquido sobre a demanda agregada é contracionista. Tal diferenciação é importante porque um aumento da parcela de lucros tem dois efeitos contraditórios sobre a taxa de lucros, que alteram o investimento (de acordo com os pressupostos teóricos adotados pelos autores), e que podem ser diretamente observados a partir da equação anterior - de um lado, aumenta diretamente a taxa de lucro, o que incentivaria e aumentaria o investimento; de outro, ao reduzir o consumo e o grau de utilização

2 A parcela de lucros na renda é frequentemente referida também pela margem de lucros. Seja $Y=(1+z) W$, em que $Y$ é a renda real, representada pela soma agregada de salários mais lucros; $W$ é o salário real e $z W$, o volume (real) de lucros descrito como margem de lucros $z$ sobre o custo salarial real; então, a parcela dos lucros na renda nada mais é do que $z W /(W+z W)=z /(1+z)$. Ou seja, a margem de lucros $z$ determina plenamente a parcela de lucros na renda. 
imediato, diminui a taxa de lucro, o que desestimularia o investimento. Se o efeito líquido sobre a taxa de lucro, e consequentemente sobre o investimento, também for contracionista, ele reforça o efeito do consumo; se for expansionista, a condição de estabilidade robinsoniana implica que esse efeito será, em valor absoluto, inferior ao efeito contracionista do consumo. Há duas hipóteses básicas por trás desse resultado. A primeira é que a propensão marginal a consumir dos trabalhadores seja maior que a dos capitalistas, a fim de que o volume de consumo agregado diminua ao se transferir renda dos primeiros para os últimos. A segunda que, se a resultante do aumento da margem sobre a taxa de lucro for positiva, a reação de aumento do investimento não gere um efeito líquido maior, em valores absolutos, do que a diminuição do volume de consumo ocorrida após a redistribuição de renda.

O acelerador forte é verificado quando:

- um dado aumento na parcela de lucros exerce redução da taxa de lucro e, por isso, efeito contracionista sobre o investimento agregado, logo, sobre o dimensionamento do estoque de capital ou da capacidade produtiva; simetricamente, um dado aumento da parcela de salários exerce efeito expansionista sobre investimento/estoque de capital/capacidade produtiva.

Então, se vale o acelerador forte, uma transferência de renda dos trabalhadores para os capitalistas, sob a manutenção da hipótese de que a propensão marginal a consumir dos primeiros é maior que a dos segundos, além de causar redução do grau de utilização num primeiro momento, esse efeito prevalece sobre a taxa de lucro, logo, sobre o investimento, fazendo este último também diminuir, ratificando o sinal de queda do grau de utilização.

Vale observar que sempre que há acelerador forte, necessariamente, também ocorre estabilidade robinsoniana (esta é uma condição necessária para aquele), mas a recíproca não é verdadeira. Possivelmente, o maior mérito dos vários trabalhos de Bhaduri e Marglin, neste tema, está exatamente em mostrar como e porquê essas duas condições seriam particulares aos modelos neokaleckianos que os antecedem. Portanto, é através da condição de acelerador forte, uma vez dada a estabilidade robinsoniana, que é suportada a condição de crescimento econômico liderado pelos salários (wage-led) dentro desse debate, só que, sublinham $B \& M$, este não deve ser considerado o único caso possível. Os autores ainda apontam que essa 
relação positiva entre salários e crescimento econômico é comumente utilizada como uma manifestação "geral" de crescimento econômico liderado pela demanda. Todavia, alegam que nada impede uma eventual relação direta entre margem e taxa de lucro e, na ocorrência dessa relação, seria possível impulsionar o crescimento através dos lucros, não dos salários, e ainda assim essa é uma forma de crescimento liderado pela demanda. B\&M (1988) comentam que a ocorrência de profit-squeeze (compressão de lucros) não deveria ser desconsiderada nos modelos neokaleckianos sobre os quais se debruçam criticamente, enfatizando que tais modelos simplesmente não abordam essa possibilidade, sem se justificar. Vamos, então, apresentar a alternativa proposta por B\&M, mas, antes disso, explicitar sinteticamente o que foi apresentado sobre a intenção teórica dos autores:

- em primeiro lugar, os autores preconizam a importância da taxa de lucro como um determinante do investimento;

- a seguir, mostram que o efeito da taxa de lucro não deve ser tratado como um todo, mas aberto em dois componentes: a) margem de lucro e b) grau de utilização;

- feito isso, mostram que, se vale o acelerador forte a partir da estabilidade robinsoniana, o componente b) sempre prevalece na determinação da taxa de lucro, logo, do investimento, e como consequência o crescimento econômico sempre será wage-led.

- finalmente, apontam que o caso anterior não pode ser tomando como caso geral, mas sim como apenas um caso possível num universo de quatro possibilidades alternativas, conforme será apresentado na próxima seção.

\section{0 modelo canônico de Bhaduri e Marglin}

Antes de entrar no modelo dos autores em questão é preciso esclarecer um ponto importante. Embora eles façam referência ao modelo de Joan Robinson, não utilizam, eles próprios, a mesma estrutura analítica daquela autora para criticá-la. No caso de Robinson, a estrutura básica de crescimento econômico se dá com um grau de utilização fixo e igual ao normal e com distribuição de renda como variável de ajuste capaz de financiar o aumento do investimento necessário ao crescimento. Este último se dá, assim, através de um mecanismo (re)distributivo para os lucros, via aumento 
de preços em relação aos salários nominais e consequente redução do salário real. Dito de outra forma, uma redistribuição de renda para os lucros só eleva o investimento e aumenta a poupança agregada porque reduz o consumo! E reduz o consumo justamente porque a propensão marginal a consumir dos salários é maior que a dos lucros e é nesse sentido específico que os salários possuem maior "peso" na determinação do volume de demanda agregada no modelo de Robinson. No caso de Joan Robinson, faz sentido usar a expressão "estabilidade", mas esta não tem nada a ver com modelos de crescimento wage-led. Antes pelo contrário, é exatamente a presença desse mecanismo de "estabilidade" que impede que o crescimento se torne wage-led. Uma redistribuição de renda a favor dos salários aumentaria, ceteris paribus, o consumo total como percentual da renda; só que isso, em vez de estimular grau de utilização e o crescimento só estimula a aumento de preços, de modo a brecar o aumento do consumo e impedindo que o crescimento seja liderado pelos salários. $O$ papel desempenhado pela redução do consumo é de, justamente, não tornar o modelo explosivo (conferindo-lhe estabilidade) porque no modelo de Joan Robinson a economia opera com restrição de capacidade. Como se pode notar, a definição de uma condição sistêmica (estabilidade robinsoniana com acelerador forte) utilizada para contemplar modelos de crescimento liderado pelos salários fica, portanto, extremamente confusa e, na verdade, ela só é possível porque B\&M, ao contrário de Joan Robinson, não consideram o grau de utilização fixo e igual ao normal. ${ }^{3}$ Os autores associam a concepção de estabilidade robinsoniana a modelos de autores como Dutt, Amadeo ou Rowthorn que, na realidade, não replicam o modelo original de Joan Robinson, apesar de serem listados como possíveis "seguidores" daquela autora, algo certamente discutível e que não nos interessa aqui. É importante sublinhar que essa diferença de abordagem sobre o grau de utilização faz com que a comparação entre os dois modelos não seja rigorosa.

O ponto de partida dos autores é a construção de uma abordagem alternativa da tradicional curva IS. Como largamente sabido, a curva IS representa os pontos de equilíbrio no mercado de bens, igualando oferta e demanda nesse mercado, ou simplesmente as decisões de poupança e investimento. Os pares renda e taxa de juros, que garantem tradicionalmente esse equilíbrio são, nessa versão, substituídos pelos pares grau de utilização, $u$, e parce$\mathrm{B} \& \mathrm{M}$ não tem qualquer papel estabilizador em um modelo com grau de utilização variável. 
la dos lucros na renda, $\sigma$. Tomemos a função poupança em nível absoluto $S$ :

$$
S=s R=s(R \mid Y)\left(Y \mid Y^{*}\right) Y^{*}
$$

com $s=$ propensão marginal a poupar, $R=$ massa de lucros e $Y^{*}=$ produto potencial. Normalizando $Y^{*}=1$, vem $S=s \sigma u$. Em equilíbrio (e sem entrar no mérito das relações de causalidade neste momento), $I=S=s \sigma u$. Dada a propensão a poupar, $s$, uma mudança no valor de $\sigma$ requer uma mudança compensatória em $u$ a fim de reequilibrar o mercado de bens, no sentido de permanecer ao longo da curva IS. Entra aí a fundamental sutileza da análise: não se pode dizer, a priori, em qual direção deve variar o grau de utilização em resposta a uma mudança na parcela relativa dos lucros. Isso dependerá, essencialmente, da direção e magnitude total da reação do investimento. A única coisa que se pode garantir numa análise em que a propensão marginal a consumir da renda auferida sob a forma de salários é maior do que aquela auferida sob a forma de lucros é que o aumento relativo da parcela dos salários eleva o componente consumo agregado e contribui, por essa via para o aumento do grau de utilização, e consequentemente surte um efeito altista sobre a taxa de lucro. Contudo, a correspondente redução da parcela relativa dos lucros surte um efeito baixista sobre a taxa de lucro. Resumindo, a questão se reduz a analisar qual dos dois efeitos prepondera sobre a taxa de lucros: caso prevaleça o efeito altista do grau de utilização, a resultante se traduz num aumento do investimento que coatua com o aumento do consumo na elevação da demanda agregada, logo, do grau de utilização. Porém, se o efeito preponderante for o baixista ocasionado pela redução da parcela dos lucros, a resposta vem numa redução do investimento; daí, há que se analisar a resultante gerada nesse processo, confrontando o aumento do consumo com a redução do investimento no total da demanda agregada. Dependendo de qual dos dois componentes da taxa de lucro prevalece, seguem-se diferentes impactos sobre o nível de investimentos, o que conduz a uma multiplicidade de situações, conforme se vê nos quatro casos a seguir.

Comecemos pelo gráfico 1. Este representa uma versão mais "comum" da curva IS, com inclinação negativa. A maiores parcelas relativas de lucro correspondem menores graus de utilização da capacidade, pois o efeito final sobre a demanda agregada é negativo. No caso em questão, o efeito sobre a demanda agregada é resultante de consumo e investimento se movendo na mesma direção. Nesse caso, B\&M fazem referência a um mecanismo de 
cooperação no sistema capitalista: as duas classes se beneficiam e, portanto, têm interesse num aumento da parcela dos salários na renda. A partir desse efeito gerado sobre a demanda, agregada, oriundo de um aumento da parcela dos salários na renda, é que os autores avançam, sem maior cuidado, para a trajetória de acumulação, mostrando que este é tipicamente um regime de crescimento wage-led: o aumento da parcela dos salários impulsiona consumo e investimento na composição da demanda agregada e, a partir daí, o investimento também cria capacidade produtiva no longo prazo. Então, embora o gráfico esteja apenas evidenciando o efeito da redistribuição sobre o grau de utilização, os autores estão igualmente preocupados com o efeito dessa redistribuição sobre o processo de acumulação.

Figura 1 Quatro casos para a curva IS
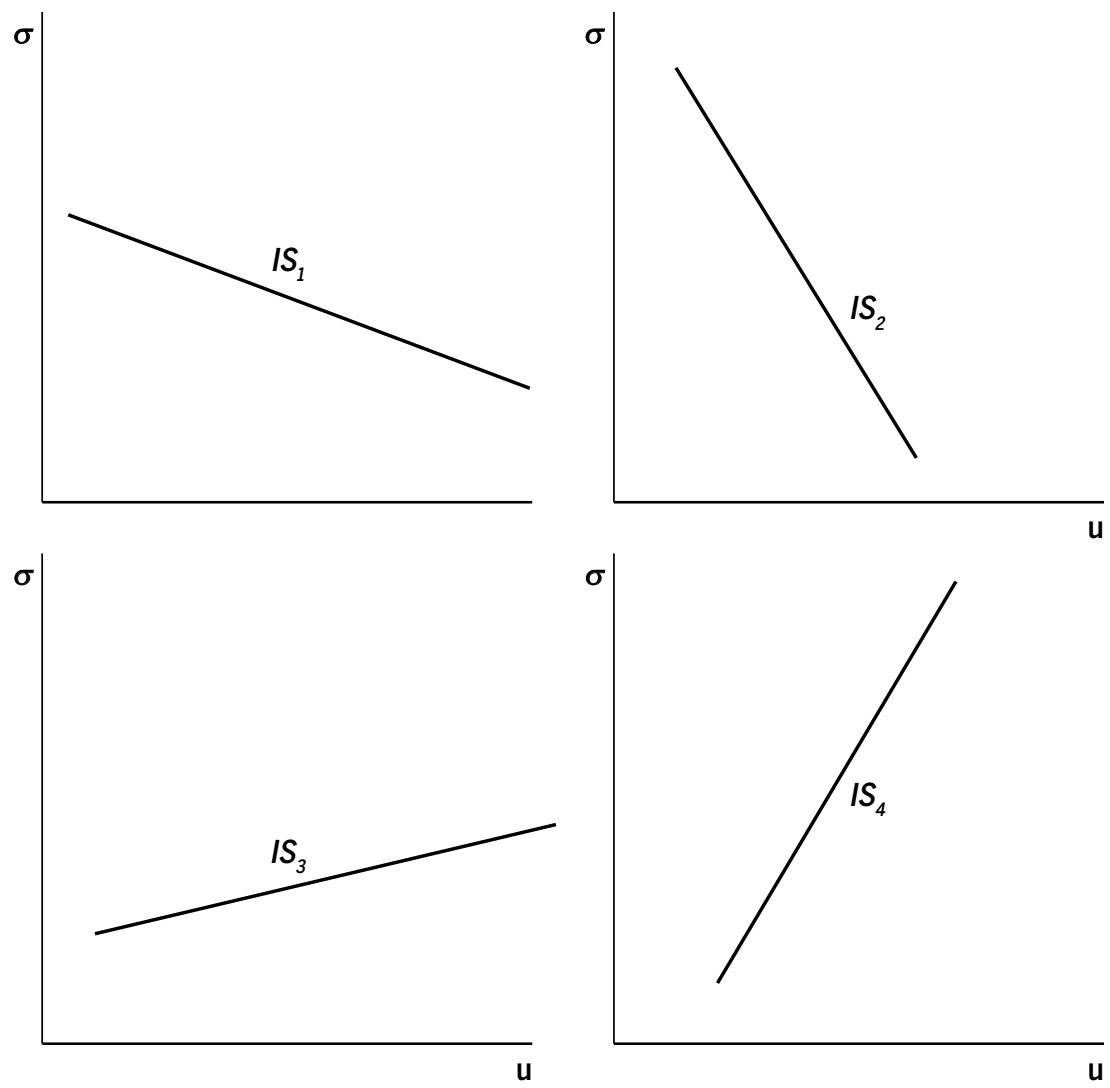

Fonte: Elaboração própria. 
gráfico 2 se diferencia do gráfico 1 no que $B \& M$ referenciam como a elasticidade da curva IS, nesse caso menor. A inclinação, ainda negativa, mantém a relação inversa entre $\sigma$ e $u$, porém nesse caso, o aumento da parcela dos lucros prevalece sobre o efeito do grau de utilização na taxa de lucro. Ainda assim o aumento do consumo prevalece sobre a redução do investimento gerando aumento líquido na demanda agregada. Mas ao contrário do caso 1 , os interesses de capitalistas e trabalhadores apontam em direções opostas e não há cooperação entre as classes. É a típica ocorrência de profit-squeeze: um aumento relativo de salários na renda, embora ainda signifique aumento líquido de demanda, não tem mais força para "puxar" o investimento e, nesse caso, devido à compressão causada na taxa de lucros (profit-squeeze), o aumento da demanda não acarreta aumento da acumulação. Uma realavancagem do crescimento pela via distributiva só poderia ser produzida, nesse caso, por um aumento da parcela dos lucros na renda. Portanto, trata-se de um regime de crescimento do tipo profit-led com conflito entre as classes. Também serão profit-led os regimes subjacentes aos gráficos 3 e 4 . Em ambos, a IS assume agora uma inclinação positiva, revelando que o efeito de um aumento da parcela dos lucros prepondera de tal forma sobre a taxa de lucro e o investimento que se sobrepõe à redução do grau de utilização ocasionada pela queda do consumo, gerando efeito líquido positivo sobre a demanda agregada e o grau de utilização.

No caso 3, a IS é mais elástica e o resultado é descrito numa peculiar ou inusitada forma de cooperação. Isso porque, dada a elevada elasticidade da curva IS, um aumento da parcela dos lucros gera efeito de tal forma positivo sobre o grau de utilização que o aumento do investimento gera aumento na massa de salários da economia como um todo; ou seja, a redução da parcela dos salários na renda (que pode ser lida pela via de uma redução do salário real decorrente de aumento de mark-up) estimula os capitalistas a elevarem a contratação de trabalhadores em magnitude suficiente para que esse efeito se sobreponha ao efeito baixista na massa de salários ocasionado pela redução da parcela dos salários. Portanto, trata-se de um regime profit-led com cooperação, mas uma cooperação específica entre os capitalistas e os trabalhadores que ainda estão desempregados (e somente estes, pois os que já estão empregados sofrem perda salarial). Finalmente, o caso 4, com IS positivamente inclinada, porém, pouco elástica, mantém a lógica profit-led, mas caracteriza-se por conflito na medida em que o au- 
mento da parcela dos lucros aumenta em magnitude menor o grau de utilização em relação ao caso anterior e, portanto, mesmo gerando aumento da contratação, não eleva a massa de salários. O conflito fica posto entre os capitalistas e a classe trabalhadora tomada como um todo, uma vez que nem mesmo a redução do salário real é suficiente para estimular um volume de contratação que cause um aumento da massa de salários agregada.

Como vemos, ao se referirem a regimes de crescimento profit ou wageled, B\&M estão evocando a condição de acumulação de capital no longo prazo. No entanto, como se pode notar pelos gráficos anteriores, o que fica evidente é basicamente a variação do grau de utilização de alguma capacidade produtiva que não é esclarecida. Embora isso deixe claro que eles estão observando as possibilidades de niveis de produção profit ou wage-led, não dá qualquer destaque específico para a observação das taxas de crescimento econômico profit ou wage-led. Tal coisa, na verdade, fica subentendida no texto e nos gráficos, mas não é explicitamente tratada. É possível intuir a dinâmica de crescimento pretendida pelos autores a partir da inclinação da curva IS, mas isso causa muita obscuridade acerca do comportamento da acumulação de capital, que deveria ser considerado com mais propriedade dentro de uma análise de crescimento econômico.

Antes de encerrar esta seção, vamos sintetizar quais foram seus principais objetivos:

- mostrar, com base na crítica de B\&M, que nem sempre uma redistribuição de renda para os salários implica maior crescimento econômico (wage-led growth), mesmo quando a propensão marginal a consumir dos trabalhadores é maior que a dos capitalistas, pois, mesmo nesse caso, pode ocorrer o chamado profit-squeeze (caso IS2), a despeito da ocorrência da estabilidade robinsoniana;

- que, somente o caso do gráfico n¹ (IS1) apresenta tanto o grau de utilização (nível de produto) quanto a taxa de crescimento, ambos liderados pelos salários e, portanto, somente esse caso contempla o acelerador forte, além da estabilidade robinsoniana discutida por B\&M.

O objetivo das próximas seções será mostrar que o caso (IS1) pode ser, na verdade, menos particular do que originalmente concebido por $\mathrm{B} \& \mathrm{M}$ (e vale notar que o principal objetivo deles era mostrar essa particularidade) e sob condições plenamente compatíveis com a tradição keynesiana, tradição esta, que os autores alegam seguir com mais propriedade do que seus antecessores. Ou seja, pretende-se mostrar que o acelerador forte a 
partir da condição de estabilidade robinsoniana, conduzindo a um regime de crescimento liderado pelos salários, não precisa constituir uma particularidade improvável.

\section{Concavidade da função consumo: uma alternativa analítica}

Nesta seção, faremos a proposição de uma função consumo utilizável em modelos neokaleckianos básicos como o de B\&M. Através disso, estenderemos a abrangência dos modelos em questão, contemplando não somente a função investimento dentro deles. Como vimos, todo o mecanismo de determinação de regimes de crescimento profit ou wage-led na seção anterior passa exclusivamente pela função investimento. No entanto, há razões teoricamente relevantes para reconsiderar a função consumo em relação ao tratamento convencional que the é dado. Por isso, uma possível forma de estender o raio de abrangência do modelo de B\&M é flexibilizando os padrões da função consumo. Mais especificamente, não parece haver motivos fortes para manter a propensão marginal a consumir constante indefinidamente, principalmente quando se trata de grupos ou classes cuja renda auferida em muito já se afasta do nível necessário à sua subsistência.

A ideia tem sua concepção inicial na "Teoria Geral" de Keynes, cuja função consumo pode ser resumida com as seguintes propriedades (ver SPANOS, 1989, p.155):

a) $O$ consumo é função estável da renda: $C=f(Y)$;

b) $0<P m g C<1, \operatorname{com} P m g C=\partial C / \partial Y=$ propensão marginal a consumir;

c) $P m e C>P m g C$, onde $P m e C=C / Y=$ propensão média a consumir;

d) A proporção consumida da renda decresce quando a renda aumenta,

$$
\text { i.e., } \frac{\partial C / Y}{\partial Y}<0 \text {. }
$$

Sobre este último item (d), Keynes (1996, p. 64-65, 119, 138, 142, 144) alega especificamente sobre a redução da $P m g C^{4}$ em resposta ao aumento da riqueza de uma comunidade. Espera-se que em sociedades mais, ou muito, abastadas, a capacidade de consumo tenha um limite relativo: por mais 
que o consumo sempre cresça com o aumento da renda, o mesmo se daria em taxas decrescentes. Deaton (1989) traz evidências sobre o comportamento diferenciado da propensão a poupar em países em desenvolvimento vis-à-vis países desenvolvidos, mostrando que as notáveis diferenças demográficas e de distribuição espacial da população conduzem a problemas de alocação de renda ao longo de vários períodos muito diferentes nos dois contextos. Se o problema existe entre países, pode-se, sem perda de generalidade, estendê-lo para o interior de um país, desde que exista significativa desigualdade regional na distribuição das atividades (rural, urbana) e principalmente desigualdade significativa na distribuição de renda. Como este parece ser o caso do Brasil, vale a pena considerar a hipótese.

fundamento de uma função consumo nos moldes apresentados é descrito pela noção de "concavidade da função consumo", presente em Carroll e Kimball (1996), Carroll (2001), também em Zeldes (1989) ou Gourinchas e Parker (2001), entre outros. A ideia é exatamente contemplar a proposta de Keynes, o que em um diagrama confrontando renda no eixo horizontal e consumo no vertical revela uma função côncava em relação à renda, na qual para valores baixos da última vê-se praticamente um paralelismo à reta de $45^{\circ}$, ao passo que para valores sucessivamente maiores de Y vê-se um achatamento progressivo da função consumo.

A maior parte dos estudos sobre consumo considera dada a distribuição de renda procurando simplesmente captar as regularidades ou padrões de consumo, seja em séries temporais para determinado país (região), seja em dados cross-section, comparando países (regiões). Mas, o padrão de concavidade na função consumo tem como uma de suas grandes utilidades analíticas, exatamente, analisar o que acontece com o consumo quando as pessoas ficam relativamente mais ricas ou mais pobres. Blinder (1975), ao testar os efeitos das mudanças distributivas sobre a propensão marginal a consumir para os Estados Unidos, conclui afirmativamente sobre a possibilidade de ocorrência, sob parâmetros empiricamente razoáveis, de duas proposições:

PROPOSITION A: The marginal propensity to consume of an individual falls as his disposable income rises. E,

PROPOSITION C: If income is taken from one individual and given to another individual who is identical in all relevant respects save that his income is higher, then total consumption will decline (Blinder, 1975, p. 448).

Pode-se, entretanto, indagar se não ocorreria uma compensação geral entre as propensões a consumir das classes e se a elevação da propensão a 
poupar de um grupo não significaria reduzi-la para outro grupo. A resposta a essa questão, ainda que especulativa, é simples: por exemplo, para uma redistribuição da renda dos mais pobres para os mais ricos, provavelmente, a redução da propensão a poupar do grupo mais pobre não deve se dar na mesma magnitude que o aumento da mesma para o grupo mais rico. Indo além disso, se o interesse do estudo for para países subdesenvolvidos, é muito provável que a propensão a poupar do grupo mais pobre já seja próxima de zero e, uma eventual redistribuição desse tipo não deve, portanto, alterar o padrão de poupança (zero!) dos mais pobres, porém com certeza alterará o dos mais ricos.

Se a redistribuição for dos mais ricos para os mais pobres, o impacto será ainda mais visível: da parcela transferida uma grande parte que era antes poupada transformar-se-á integralmente em consumo. Carroll e Kimball (1996) também alertam para a importância da concavidade da função consumo quando se considera a questão distributiva:

Concavity of the consumption function is interesting for several reasons. The most important is probably that strict concavity implies that consumption growth depends on the level of wealth, which is serially correlated, so the implication of Hall (1978) that consumption should follow a random walk at the household level no longer holds. In practice, most Euler equation tests have implicitly assumed that the consumption function is linear, or approximately linear. At the aggregate level, concavity means that the entire wealth distribution is an omitted variable when estimating aggregate consumption Euler equations, and so the random walk implication again fails (Carroll e Kimball, 1996).

A concavidade da função consumo aparece tipicamente com a introdução de incerteza, ou mais exatamente, de comportamentos não indiferentes ao risco por parte dos agentes. O trabalho de Zeldes (1989) é um dos pioneiros dessa perspectiva. Esse autor faz detalhado trabalho com experimentos computacionais buscando comparar dois quadros para padrões de consumo: um quadro com o chamado "equivalente de certeza" na função consumo, associando-a à teoria do ciclo de vida, e outro quadro com a adição de incerteza ao cenário anterior, o que altera significativamente a função utilidade e a função consumo. Os ativos financeiros passam a desempenhar um papel decisivo no segundo quadro, tornando-se fundamental avaliar o volume atual dos mesmos vis-à-vis à renda futura esperada; quanto mais baixa essa relação maior tende a ser a incerteza e mais côncavo o formato da função consumo; isto se diferencia sobremaneira do quadro típico de suavização do consumo ao longo da vida presente num cenário com equivalente de certeza. Numa realidade em que o futuro é incerto, riqueza 
acumulada, incluindo o volume de ativos desempenham papel-chave na determinação ou não de uma poupança precaucional que vai sendo sistematicamente contrabalançada com a renda corrente percebida e também a esperada. A propensão marginal a consumir assume valores maiores para menores razões entre ativos acumulados e renda futura esperada. Assim, para baixos valores auferidos de renda no presente, associados a baixo volume de riqueza, menor a razão entre volumes de ativos acumulados e renda futura esperada e maior a propensão marginal a consumir de renda/ riqueza presente comparada à futura. Já as funções consumo associadas à renda permanente, largamente utilizadas como padrão, mantêm a hipótese de proporcionalidade, que implica uma propensão a consumir constante da renda média esperada ao longo da vida, referência para o agente num quadro de certeza.

A conclusão do artigo de Zeldes traz um alerta para os possíveis problemas advindos do uso de modelos com equivalente de certeza e para o papel central exercido pela poupança precaucional em quadros de incerteza. Igualmente concluem Gourinchas e Parker (2001) que riscos sobre a renda conduzem a uma regra de consumo estritamente convexo e à possibilidade de falha da hipótese da renda permanente como aproximação razoável do comportamento do consumo, tanto em nível individual, quanto agregado. Corroborando, Caroll (1997; 2001) e Carroll et al. (1992) fazem estudos bastante minuciosos sobre poupança precaucional, tendo sempre em vista seu caráter regulador sobre as oscilações de renda e, por isso, a poupança tende a aumentar como parcela da renda nos períodos de "maior riqueza" maiores rendimentos etc. A expectativa de desemprego é também explicitamente incorporada ao conceito de incerteza. Esses estudos também tentam captar o comportamento do consumo relacionado à expectativa de vida dos agentes, mas, de novo, sem abrir mão da incerteza. A ideia é que, tão somente no último período de vida, o agente não poupa da mesma forma que nos outros períodos e só nessa fase é que a função consumo muda muito, podendo perder a concavidade. Já nos 10 anos antes do fim da vida, por exemplo, o comportamento é muito similar àquele de 50 anos antes do fim. As demais características da função, exceto para o fim da vida, mantêm-se qualitativamente as mesmas relatadas pelos demais autores. 
Figura 2 Regra de consumo ótimo considerando os anos restantes de vida

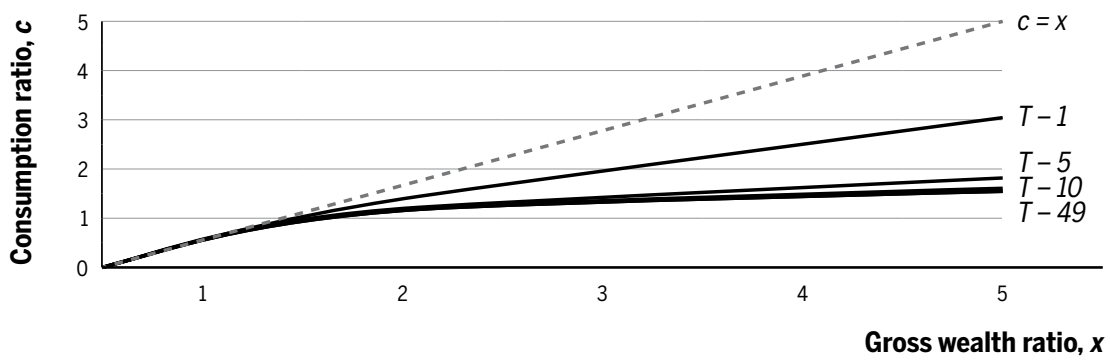

Fonte: Carroll et al. (1992).

A partir desse referencial, torna-se pouco interessante que as pesquisas sobre padrões de consumo avancem apenas baseadas em cenário de previsão perfeita ou ausência de incerteza.

Além disso, como o consumo representa, praticamente em qualquer lugar, a maior fonte de demanda agregada e de geração de renda, e uma vez que se acredite que o crescimento é liderado pela demanda, é mais provável que um modelo capaz de endogeneizar pelo menos uma parte do consumo deva também prever que a reação dos investimentos a " $u$ " gere mais impacto que a reação dos investimentos a " $\sigma$ ". Esse poderia, portanto, ser um bom caminho para justificar o acelerador forte de B\&M e é isso que vamos testar na sequência deste artigo.

\section{A função consumo côncava e o crescimento lidera- do pelos salários}

Com base no que vimos até aqui, assumiremos como hipótese que a $P m g C$ deve diminuir conforme aumenta a renda. Mas como exatamente seria conveniente endogeneizá-la? Com apenas duas classes, capitalistas e trabalhadores, manteremos a hipótese usual de que a PmgC dos trabalhadores é maior que a dos capitalistas. Essa hipótese baseia-se no fato de que a renda do trabalho encontra-se relativamente mais próxima do nível de subsistência do que se encontra a renda auferida sob a forma de lucros e que, portanto, menos renda do trabalho sobra para constituição de poupança. Simplificadamente estamos assumindo uma economia dividida em dois grupos: um "mais pobre", dos trabalhadores; outro "mais rico", dos 
capitalistas. A princípio, vamos assumir uma forma linear para a $\mathrm{PmgC}$ de qualquer das classes, negativamente relacionada com a parcela da renda auferida pela respectiva classe, como:

$$
\varphi=\Phi-\alpha(\sigma),[0<\Phi \leq(1+\alpha \sigma)] \text { e }(0<\alpha<1)
$$

onde $\sigma$ representa, provisoriamente, a parcela da renda sob a forma do rendimento de uma determinada classe qualquer. A margem de variação dos parâmetros descrita na equação (3) se explica considerando-se um valor positivo para $\Phi$, a não ocorrência de endividamento (o que limita a $P m g C$ à unidade) e a existência de algum componente autônomo positivo na sua definição, a fim de contemplar acréscimos nos gastos que não sigam um padrão proporcional preciso com respeito aos acréscimos de renda.

Com o mesmo parâmetro " $\alpha$ " para ambas as classes, não conseguiremos gerar a distinção de comportamento descrita acima, pois ambas as classes pouparão exatamente o mesmo percentual " $\alpha$ " de suas respectivas rendas. Assim, denominando " $\alpha$ " coeficiente de poupança, o correto seria estabelecê-lo diferenciadamente entre as classes a fim de contemplar a concavidade da função consumo. Nessa diferenciação, entretanto, precisamos manter a ideia de que para percentuais mais elevados de participação na renda correspondem maiores coeficientes de poupança. Precisamos, portanto, e apenas, garantir que a variação da propensão marginal a poupar do grupo mais pobre seja menor do que a variação da propensão marginal a poupar do grupo mais rico. Uma forma simples de fazer isso seria estabelecer que, a partir de certo valor de $\sigma$, a propensão marginal a poupar aumente; e para valores de $\sigma$ inferiores a esse mínimo, ela se mantenha constante. Ou seja, para o grupo mais pobre a variação mencionada seria zero e para o grupo mais rico, a variação seria positiva. Novamente, a maneira aparentemente mais simples de fazer isso, sem perder a substância central do argumento, é tornar a $P m g C$ dos trabalhadores igual a 1 e utilizar a forma linear acima para descrever somente o comportamento da $\mathrm{PmgC}$ da renda auferida sob a forma de lucros. Dessa forma, fica mantida a ideia de que para rendas maiores, correspondem também maiores propensões marginais a poupar, ou simetricamente, menores propensões marginais a consumir, o que se diferencia da forma tradicional de uma função com propensão marginal a consumir sempre constante, contemplando a concepção de concavidade no consumo. Felizmente, também temos argumentos que acatam essa even- 
tual simplificação, tanto em Carroll (2001) como em Deaton (1991). O argumento básico deste último consiste em acrescentar restrição de liquidez na função consumo para baixos níveis de renda. Captando a interação entre poupança precaucional e tal restrição, mostra-se que a "incapacidade de tomar empréstimos em tempos ruins fornece motivo adicional para acumular ativos em tempos bons, mesmo para consumidores impacientes" (p. 1222).

A simplificação funcional proposta para a função consumo, além de evitar que um mesmo parâmetro $(\alpha)$ atinja igualmente quaisquer parcelas distributivas, referentes a diferentes classes na renda, também apresenta menor risco de gerar outro equívoco, que ocorreria se utilizássemos a mesma especificação linear proposta em (3), para, além dos lucros, captar também o comportamento da $P m g C$ dos salários. Formalmente, temos a parcela dos salários na renda como $(1-\sigma)=W a$, onde $W$ é o salário nominal e a é o coeficiente técnico de trabalho $(=L / Y)$. Portanto, $(1-\sigma)$ aumenta tanto com a variação do salário nominal (para simplificar, suponhamos os preços constantes) quanto com uma mudança tecnológica para uma forma mais trabalho-intensiva. Com isso, usando o comportamento sugerido para a função consumo aqui proposta, capta-se apenas a parcela dos salários na renda oriunda de alterações no salário (o que, na tradição de Kalecki, corresponde a uma redução de mark-up das firmas) e não oriunda de uma tecnologia mais trabalho intensiva.

\section{Figura 3 Função consumo para diferentes funções utilidade}

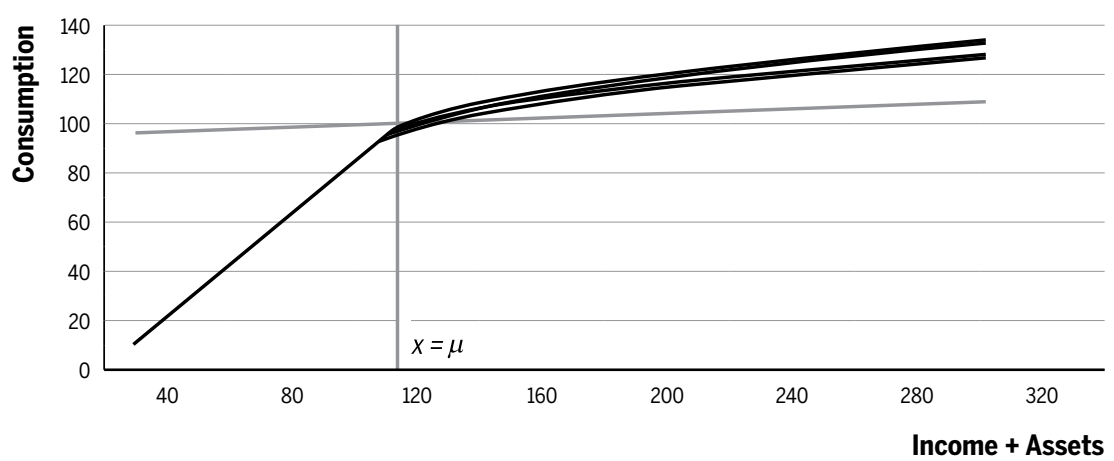

Fonte: Deaton (1991, p. 1228).

Poder-se-ia, a princípio, argumentar: mas quem garante que o mesmo não se aplicaria à renda auferida sob a forma de lucros? A resposta passa 
pela ideia de que um aumento da parcela dos lucros na renda seria muito mais provável por conta de uma elevação do mark-up do que por conta de um aumento do número de capitalistas atuando na economia: a incorporação de novos capitalistas ao sistema econômico (mantidos por tempo grande o suficiente para contemplar uma análise de longo prazo) requer, no mínimo, que se mature o tempo para estabelecer novas firmas e adquirir espaço no mercado; e requer, se sofisticarmos um pouco mais, que se tenha o mínimo de inventividade, seja para implementar inovações de produto ou de processo, ainda que marginais, capazes de justificar sua presença num mercado de concorrência (minimamente) imperfeita. Formalmente, podemos estabelecer a regra de formação de preços via mark-up como:

$$
P=(1+z) W a=(1+z)(1-\sigma)
$$

onde $(1+z)$ é o fator de mark-up, $W$, o salário nominal, $\sigma$ é a parcela dos lucros na renda (logo, $(1-\sigma)$ é a parcela dos salários na renda). Portanto, um aumento de $\sigma$ para um mesmo $P$ pode se dar através de elevação de $z$, queda de $W$ ou queda de $a$. Nenhum dos três modos requer elevação no número de capitalistas para elevar $\sigma$. Particularmente, no caso da mudança tecnológica com redução de $a$, aumentando a produtividade do trabalho, não é necessário aumentar o número de capitalistas, ao contrário do caso simétrico, no qual era necessário aumentar o número de trabalhadores.

Dito isso, voltemos a assumir a expressão 1 como sendo a propensão marginal a consumir oriunda dos lucros e supor que aquela oriunda dos salários é igual a 1. Para viabilizar essa abordagem vamos fazer outra extensão, desta vez no modelo pós-keynesiano apresentado em Dutt (2003). A função consumo agregada será composta, portanto, da seguinte forma:

$$
C=(1-\sigma) Y+\varphi \sigma
$$

Ou seja

$5 \mathrm{Na}$ equação que se segue, para que a $P M g C$ dos trabalhadores seja maior que a dos capitalistas é necessário que $\varphi<1$ seja imposto. Ou seja, $\Phi-\alpha \sigma<1$, ou , $\Phi<1+\alpha \sigma$. Como, de acordo com a equação (3), $\Phi>0$, a condição necessária é $1+\alpha \sigma>0$, logo $1>-\alpha \sigma$. Como $\sigma$, a parcela dos lucros na renda nunca pode ser negativa e como também $0<\alpha<1$, a condição é satisfeita. 


$$
C=(1-\sigma) Y+[\Phi-\alpha(\sigma)] \sigma Y
$$

que gera:

$$
C=Y\left[(1-\sigma)+\Phi \sigma-\alpha \sigma^{2}\right]
$$

O investimento, apenas no curto prazo, manter-se-á descrito como:

$$
I=g K
$$

Mas, diferentemente de Dutt (2003) não vamos mais manter o mark-up constante. pois é da variação dele que provém a variação das parcelas distributivas, o que, para efeitos de análise de regimes de crescimento profit e wage-led precisa ser contemplado. Assim, a taxa de lucro será determinada por:

$$
r=\sigma u
$$

onde $u$ é o grau de utilização da capacidade produtiva. Ficamos com:

$$
Y=Y\left[(1-\sigma)+\Phi \sigma-\alpha \sigma^{2}\right]+g K
$$

Normalizando (8) por $Y$ e tomando a versão neokaleckiana de $u$, na qual $u=Y / K^{6}$ vem o equilíbrio de curto prazo como função de $u$ :

$$
u^{*}=\frac{g}{\sigma-\Phi \sigma+\alpha \sigma^{2}}
$$

Lembrando que $\Phi<1+\alpha \sigma$, vê-se que o grau de utilização de equilíbrio está inversamente relacionado com a parcela dos lucros na renda, $\sigma$ (ver Apêndice).

$$
\frac{\partial u}{\partial \sigma}<0
$$

6 A expressão exata de $u$ é $u=Y / Y^{*}$. Entretanto, esta outra versão se popularizou, principalmente entre neo-kaleckianos, após vários trabalhos de Lance Taylor que supõem que a relação técnica capital/produto potencial é igual a 1. Ou seja, podemos escrever $u=(Y / K) .\left(K / Y^{*}\right) \operatorname{com} K / Y^{*}=1, \log 0 u=Y / K$. 
Dentro do quadro proposto por B \& M, portanto, a extensão apresentada ao modelo gera uma curva IS negativamente inclinada, como mostra a equação (10): uma variação positiva de $\sigma$ requer uma diminuição de $u$, a fim de manter o equilíbrio do mercado de bens. Este é um resultado que pode ser chamado de curto (ou médio) prazo porque avalia o impacto da mudança distributiva sobre o grau de utilização para uma dada capacidade produtiva. Como neste caso o investimento ainda é tratado autonomamente, e por isso expresso apenas em termos de variação do estoque de capital, ele não expressa reação à variação total do grau de utilização ou à margem de lucros (ou seja, a nenhum dos componentes isolados da taxa de lucro) por enquanto. Isso torna esperado que a redistribuição para os lucros reduza, inequivocamente, o grau de utilização já que tal redistribuição só afeta o consumo, não o investimento, e os capitalistas têm propensão a consumir menor que os trabalhadores. ${ }^{7}$ No longo prazo, a função investimento apresenta seu padrão de reação completo (a $u$ e $\sigma$ ) e faz variar a capacidade produtiva. Os resultados de longo prazo, isto é, sobre a acumulação de capital da economia (e não apenas sobre o grau de utilização) podem contemplar os quatro casos previstos nos gráficos anteriores.

Para isso, vamos introduzir outra pequena modificação sobre a proposta de Dutt (2003). O estoque de capital desejado variará com a taxa de lucro, $r$, porém reagindo em magnitudes diferentes sobre seus dois componentes $(\sigma, u)$. A reação separada para esses componentes cumpre explicitamente a sugestão de B\&M (1990, p. 380) como a forma mais apropriada de descrever o investimento. Assim:

$$
I=g^{d}=\gamma_{0}+\gamma_{1} \sigma+\gamma_{2} u
$$

Continuando com Dutt (2003), temos:

$$
\frac{d g}{d t}=\dot{g}=\Lambda\left(g^{d}-g\right)
$$

Substituindo (11) em (12) e tendo em vista que, no longo prazo $\dot{g}=0$, chega-se ao valor de equilíbrio da taxa de acumulação no longo prazo:

7 Entretanto, Blecker (2002) mostra que se a função investimento for linear ou Cobb-Douglas em $u$ e $\sigma$ o resultado de uma IS negativamente inclinada é replicado no modelo de B\&M, provando que o grau de utilização sempre diminui quando aumenta a parcela de lucros na renda (IS $1 S_{1}$ e $I S_{2}$ do nosso gráfico). Portanto, os outros dois casos previstos seriam válidos apenas para funções investimento não lineares. 


$$
g^{*}=\frac{\gamma_{0}+\gamma_{1} \sigma^{2}(1-\varphi)}{\sigma(1-\varphi)-\gamma_{2}}
$$

$\operatorname{com} \frac{\partial g^{*}}{\partial \sigma}<0$, desde que a propensão marginal a poupar, $s$ (observar que $s=\sigma(1-\varphi))$, satisfaça ao intervalo $\gamma_{2}<s<2 \gamma_{2}+\frac{\gamma_{0}}{\gamma_{1} \sigma}$ (ver Apêndice).

O intervalo acima confere uma muito folgada margem para variação da poupança, que está limitada inferiormente pela condição básica de estabilidade keynesiana, ${ }^{8}$ e superiormente por um valor maior do que o dobro do coeficiente de reação dos investimentos ao grau de utilização. Dentro desse intervalo, a análise das derivadas parciais nos permite dizer que a taxa de acumulação no longo prazo varia inversamente com a parcela dos lucros na renda, a condição de acelerador forte, o que confirma a sugestão da extensão proposta, sob os parâmetros sugeridos. Ou seja, nesse caso, a curva IS será negativamente inclinada e muito elástica, nos termos da segunda seção. Isso inviabiliza a ocorrência de profit-squeeze e, para qualquer mudança exógena na distribuição, o modelo se comporta da forma wage-led.

Isso porque, nesta extensão, diferentemente do modelo canônico de $\mathrm{B} \& \mathrm{M}$, uma redução de $\sigma$, apesar de manter a reação do investimento à parcela dos lucros na renda, acentua reação sobre o grau de utilização, pois reduz $s$ mais do que antes, o que aumenta ainda mais o multiplicador, aumentando $u$ e, logo, o peso de u sobre o investimento. A restrição superior sobre a propensão a poupar é apenas o resultado de uma parcela de lucros criticamente alta. Como a variável exógena nesse modelo é a distribuição de renda, a propensão a poupar assumirá valores criticamente altos para parcelas de lucro inicialmente muito altas. Mas é a parcela de lucros alta que, a partir de certo valor crítico, poderá ter relativamente maior peso que o peso do grau de utilização sobre o investimento. Por outro lado, quanto maior a propensão a poupar, menor será o grau de utilização resultante e maior a tendência de queda do investimento. Por isso fica tão difícil o modelo ser profit-led; quanto mais se redistribui renda para os lucros, mais será necessário contar com o peso da parcela dos lucros sobre a função investimento, uma vez que o peso do grau de instabilidade no balanceamento entre demanda e oferta. 
de utilização só se acentuará, tendendo a reduzir e não a aumentar o investimento. Portanto o modelo só poderia ser profit-led dentro de uma situação muito específica, na qual o peso da parcela de lucros fosse muito alto e/ou o peso do grau de utilização fosse muito baixo na função investimento para fazer com que o investimento aumentasse quando de uma redistribuição de renda para os lucros. E isso só deve ocorrer para valores inicialmente já muito altos da parcela de lucros, pois estes fazem com que o peso resultante da parcela de lucros seja alto (para um dado coeficiente de reação dos investimentos à parcela de lucros) ao mesmo tempo que o peso resultante do grau de utilização seja baixo (para um dado coeficiente de reação dos investimentos ao grau de utilização) apenas porque a parcela dos salários resulta muito baixa, de modo que a queda do grau de utilização não seja capaz de causar mais redução no investimento do que o aumento causado pelo aumento da parcela de lucros. Esse valor crítico da parcela de lucros resultará num valor crítico correspondente da propensão a poupar, e somente a partir desse valor crítico o aumento dessa propensão a poupar (e, logo, a redução de u) não terá mais força suficiente para reduzir o investimento, dado o parâmetro de reação do investimento ao grau de utilização.

Em geral, assume-se apenas que esses parâmetros são exógenos, determinados por condições estruturais da economia. Dado isso, podemos afirmar que o intervalo proposto para $s$ é condição suficiente para que o modelo seja wage-led. No entanto, também é possível notar que, se o próprio parâmetro de reação do investimento ao grau de utilização for, ele próprio, suficientemente alto, o limite superior da propensão a poupar mencionado poderá ser ultrapassado sem que o modelo se torne profitled. Precisamente, é fácil mostrar que basta que o coeficiente de reação do investimento ao grau de utilização, $\gamma_{2}$, seja maior que $\left(0,5-\frac{\gamma_{0}}{2 \gamma_{1} \sigma}\right)$ para que já seja impossível haver crescimento profit-led, mesmo que, no limite, os lucros tendam para $100 \%$ da renda e a propensão a consumir dos capitalistas para zero (ambos marginalmente abaixo desses limites); os demais valores de $\gamma_{2}$, entretanto, só exigem que a propensão a poupar não supere o limite superior mostrado acima. 


\section{Conclusão}

Este artigo ofereceu uma alternativa de expansão do conceito denominado por $\mathrm{B} \& \mathrm{M}$ de acelerador forte e, consequentemente, da possibilidade de crescimento liderado pelos salários. Isso afastou a possibilidade de profitsqueeze da família de modelos neokaleckianos que antecedem B\&M, considerando que estes autores argumentam que a ocorrência desse quadro permanecia logicamente possível e bastante provável em tais modelos. Como um possível argumento para afastar essa possibilidade, foi apresentada uma hipótese de endogeneização da propensão a consumir dos lucros à parcela destes na renda. A relevância da hipótese oferecida vai além de uma eventual solução algébrica do modelo, mas está ligada a razões teóricas e empíricas consideravelmente sólidas. Entre as razões possíveis para sugerir a hipótese proposta, três merecem destaque. Primeiro porque, sem dúvida, um modelo que se pretende keynesiano em alguma medida, com centralidade no papel da demanda, deve ter boas razões para levar adiante as principais ideias de Keynes quanto aos componentes da demanda agregada, consumo e investimento; e o primeiro, tem sido sistematicamente ignorado quanto ao aspecto da redução da propensão marginal a consumir para elevações no nível de renda. Segundo porque modelos que manipulam alterações na distribuição de renda não devem prescindir de seus importantes impactos sobre a propensão a consumir das classes, que conforme mostrado, não são desprezíveis. Terceiro porque se se considera importante incorporar a incerteza sobre a definição dos padrões de consumo, então, uma boa forma de fazê-lo está no uso do conceito de concavidade proposto no texto.

\section{Referências}

BHADURI, A.; MARGLIN, S. Profit Squeeze and Keynesian Theory. WIDER Working Paper, n. 39, April, 1988. Reimpresso em The Golden-Age of Capitalism - Reinterpreting The Postwar Experience. MARGLIN, S.; SCHOR, J. (Ed). Oxford: Clarendon Press, 1990.

BHADURI, A.; MARGLIN, S. Unemployment and The Real Wage: The Economic Basis for Contesting Political Ideologies. Cambridge Journal of Economics, v. 14, pp. 375-393, 1990.

BLECKER, R. A. Distribution, Demand and Growth in Neo-Kaleckian Macro-Models. In: SETTERFIELD, M. (Ed.). The Economics of Demand-Led Growth. Challenging the SupplySide Vision of the Long-Run. Massachusetts, USA: Edward Elgar Publishing, 2002. 
BLINDER, A. S. Distribution Effects and the Aggregate Consumption Function. Journal of Political Economy, v. 83, n. 3, jun. 1975, pp. 447-475.

CARROLL, C. D.; HALL R. E.; ZELDES S. P. The Buffer-Stock Theory of Saving: Some Macroeconomic Evidence. Brookings Papers on Economic Activity, v. 2, pp. 61-156, 1992.

CARROLL C. D.; KIMBALL M. S. On the Concavity of the Consumption Function. Econometrica, v. 64, n. 4, pp. 981-992, Jul. 1996.

CARROLL. C. D. Buffer-Stock Saving and the Life Cycle/Permanent Income Hypothesis. The Quarterly Journal Of Economics, v. CXII, Issue 1, Feb. 1997.

CARROLL. C. D. A Theory of the Consumption Function, with and without Liquidity Constraints. The Journal of Economic Perspectives, v. 15, n. 3, pp. 23-45, Summer 2001.

DEATON, A. Saving in Developing Countries: Theory and Review. Proceedings of the World Bank Annual Conference on Development Economics. The World Bank, 1989.

DEATON A. Saving and Liquidity Constraints. Econometrica, v. 59, n. 5, pp. 1221-1248, Sept. 1991.

DUTT. A. K. New Growth Theory, Effective Demand, and Post-Keynesian Dynamics. In: Old and New Growth Theories. An Assessment. Edited by Neri Salvadori. Edward Elgar Publishing. 2003

GOURINCHAS, P. O.; PARKER, J. A. (2001). Precautionary Savings - The Empirical Importance of Precautionary Saving. Aea Papers and Proceedings, v. 91, n. 2, May 2001.

KEYNES, J.M. A teoria geral do emprego, do juro e da moeda. São Paulo: Nova Cultural, 1996.

ROBINSON, J. Ensaios sobre a teoria do crescimento econômico. São Paulo: Nova Cultural, 1997.

SPANOS, A. Early Empirical Findings on the Consumption Function, Stylized Facts or Fiction: A Retrospective View. Oxford Economic Papers, New Series, v. 41, n. 1, pp. 150-169, 1989.

ZELDES, S. P. Optimal Consumption with Stochastic Income: Deviations from Certainty Equivalence. The Quarterly Journal of Economics, v. 104, n. 2, pp. 275-298, May 1989.

\section{Sobre a autora}

Vivian Garrido-vivian_garrido@yahoo.com.br

Pesquisadora de pós-doutorado do PPGEco, Universidade Federal de Santa Catarina, Florianópolis, Santa Catarina, Brasil. ORCID: https://orcid.org/0000-0002-3326-4737.

\section{Sobre o artigo}

Recebido em 03 de outubro de 2016. Aprovado em 28 de março de 2017. 


\section{APÊNDICE}

Equação (9)

$$
\begin{aligned}
& u^{*}=\frac{g}{\sigma-\Phi \sigma+\alpha \sigma^{2}} \\
& \frac{d u^{*}}{d \sigma}=\frac{-g(1-\Phi+2 \alpha \sigma)}{\left(\sigma-\Phi \sigma+\alpha \sigma^{2}\right)^{2}}
\end{aligned}
$$

Se $g>0$, então, somente se $(1-\Phi+2 \alpha \sigma)>0$, a respectiva derivada será negativa.

Mas, $(1-\Phi+2 \alpha \sigma)>0$ pois $(0<\Phi \leq 1+\alpha \sigma),(0<\alpha<1)$ e $(0<\sigma<1)$.

$$
\text { Portanto, } \frac{d u^{*}}{d \sigma}<0 \text {. }
$$

\section{Equação (13)}

$$
\begin{aligned}
& g^{*}=\frac{\gamma_{0}+\gamma_{1} \sigma^{2}(1-\varphi)}{\sigma(1-\varphi)-\gamma_{2}} \\
& \frac{d g}{d \sigma}=\frac{\left\{2 \gamma_{1} \sigma(1-\varphi)\left[\sigma(1-\varphi)-\gamma_{2}\right]\right\}-\left\{\left[\gamma_{0}+\gamma_{1} \sigma^{2}(1-\varphi)\right](1-\varphi)\right\}}{\left[\sigma(1-\varphi)-\gamma_{2}\right]^{2}}
\end{aligned}
$$

Como todos os parâmetros da equação possuem valores no intervalo entre 0 e 1 , temos que os dois termos principais do numerador (entre chaves) são, individualmente, positivos. Como o denominador da equação é necessariamente positivo, o sinal da derivada depende apenas da diferença entre os dois termos do numerador.

Colocando $(1-\varphi)$ em evidência no numerador:

$$
\begin{aligned}
& (1-\varphi)\left\{2 \gamma_{1} \sigma\left[\sigma(1-\varphi)-\gamma_{2}\right]-\left[\gamma_{0}+\gamma_{1} \sigma^{2}(1-\varphi)\right]\right\} \\
& =(1-\varphi)\left\{2 \gamma_{1} \sigma^{2}(1-\varphi)-2 \gamma_{1} \gamma_{2} \sigma-\gamma_{0}-\gamma_{1} \sigma^{2}(1-\varphi)\right\} \\
& =(1-\varphi)\left\{\gamma_{1} \sigma^{2}(1-\varphi)-2 \gamma_{1} \gamma_{2} \sigma-\gamma_{0}\right\}
\end{aligned}
$$


Dividindo e multiplicando a expressão acima por $\gamma_{1} \gamma_{2} \sigma$, vem:

$$
\left[(1-\varphi) \gamma_{1} \gamma_{2} \sigma\right] \cdot\left[\frac{\sigma(1-\varphi)}{\gamma_{2}}-2-\frac{\gamma_{0}}{\gamma_{1} \gamma_{2} \sigma}\right]
$$

O primeiro termo é sempre positivo (lembrando que a condição $\varphi<1$ já foi mencionada na nota $n^{\circ} 3$ ). Portanto, para que a derivada seja negativa é preciso que $\frac{\sigma(1-\varphi)}{\gamma_{2}}<2+\frac{\gamma_{0}}{\gamma_{1} \gamma_{2} \sigma}$.

Rearranjando:

$$
\sigma(1-\varphi)<\left(2 \gamma_{2}+\frac{\gamma_{0}}{\gamma_{1} \sigma}\right) \text {, ou seja, a propensão marginal a poupar da eco- }
$$

nomia pode assumir valores que vão até pouco mais que o dobro do coeficiente de reação dos investimentos ao grau de utilização para que o crescimento seja liderado pelos salários. Além disso, podemos também acrescentar a condição de estabilidade keynesiana, que garante, concomitantemente, a estabilidade de modelos keynesiano/kaleckianos. Para isso, é necessário que a propensão a poupar seja maior do que o mesmo coeficiente de reação ao grau de utilização, ou seja, $\sigma(1-\varphi)>\gamma_{2}$. Juntando essas duas informações:

$$
\gamma_{2}<\sigma(1-\varphi)<2 \gamma_{2}+\frac{\gamma_{0}}{\gamma_{1} \sigma}
$$

